\title{
DIVERSIDADE SEXUAL E SUA PROTEÇÃO: ANTINOMIAS E CONTRASSENSOS POLÍTICOS DA CRÍTICA CRIMINOLÓGICA FRENTE À NECESSIDADE DE TUTELA PENAL ${ }^{1}$
}

SEXUAL DIVERSITY AND ITS PROTECTION: POLITICAL ANTINOMIES AND CONTRADICTIONS OF CRIMINOLOGICAL CRITICISM REGARDING THE NEED FOR CRIMINAL CONTROL

Gabriel Antinolfi Divan

Carolinne Nhoato dos Santos

\section{RESUMO}

0 presente trabalho se propõe à discussão da aparente contradição causada no panorama criminológico-crítico a partir do pano de fundo do debate sobre providências legais de criminalização de condutas homofóbicas no Direito brasileiro. Utiliza a revisão bibliográfica de ideias-cânone da crítica criminológica em comparação a dados numéricos consolidados para, em um primeiro momento, buscar credenciais que legitimem o debate sobre a tutela penal da temática. Em um segundo, demonstra que existe a necessidade de um discurso crítico ser permeável a constatações empíricas e a agendas político-criminais relevantes, sem que isso o faça perder o tom crítico essencial.

Palavras-chave: Criminologia Crítica; Dignidade constitucional; Homofobia.

\section{ABSTRACT}

The present work aims to discuss the apparent contradiction caused in the criminological-critical panorama from the background of the discussion of the 
criminalization (in a broad sense) of homophobic behavior in brazilian law. It uses the bibliographical review on some canons of criminological criticism in comparison to numerical condolidated data, in order to, at first, seek credentials that legitimize the debate on the criminal tutelage of the subject. Second, it demonstrates that there is a need for a critical discourse to be permeable to empirical findings and relevant political-criminal agendas, without meaning loss of original character.

Keywords: Critical Criminology, Constitutional relevance; Homophobia.

\section{INTRODUÇÃO}

0 debate acerca da necessidade de racionalização da tutela estatal de bens jurídicos penalmente relevantes e, mormente, constitucionalmente dignos (na esteira do que propuseram DOLCINI; MARINUCCI, 1994, p. 185) soa tal um lugar comum, tanto no campo de leitura dogmático-penal minimalista, quanto a aquele que se aproxima - sob certo aspecto - às discussões na seara da criminologia de cunho crítico.

Não há que se referir motivação mais explícita para a defesa de tal perspectiva no quesito, uma vez que se parte da premissa dúplice de cunhos democrático e político quanto à necessidade de filtragem e humanização dos mecanismos de controle penal. 0 que, não raramente, se adequa perfeitamente à ideia de, por um lado (a) sua minimização, e (b) o refrear constante de sua ampliação indevida ou leviana.

Há muito, no entanto, os debates - tanto aquele pela ótica criminológica, quanto pelo viés penal-minimalista - já não ser limitados exclusivamente nos confins de uma oposição simples entre políticas criminais expansivas e discursos de maximização, de um lado, e, de outro, por combate à expansão como única e exclusiva bandeira das críticas (sejam criminológicas, sejam dogmáticas). Ingredientes políticos e mesmo ideológicos forçam a necessidade de ingresso na pauta das discussões e transmutam alguns dos campos e premissas, gerando entrecruzas e quebra de fronteiras discursivas.

Se outrora (e mesmo, ainda) para muitos, o papel, por exemplo, de um arcabouço criminológico que se diz crítico, seria o de barragem instantânea à criação ou reconstrução de tipos penais inovadores e à 
alçada de mais bens jurídicos à categoria de tuteláveis penalmente ocasionando um maior alcance do sistema jurídico-penal como um todo - não há falsear nem dissimulação, necessariamente, ao se propor ideia antagonista. E, veja-se que em relação a sistema jurídico-penal, trata-se, aqui, inclusive, da atuação encadeada de todos os órgãos, aparelhos legais e mecanismos que se interpenetram e se auto complementam - como na síntese de Divan (2015, p. 62) para os conceitos acopláveis de Hassemer (2005, p. 416-417) e Zaffaroni, Alagia e Slokar (2002, p. 18-19), quando esses falam em "sistema penal".

A seletividade penal (pedra de toque tão cara ao discurso crítico deslegitimador, em todas suas vertentes), opera também no sentido inverso: há um cunho político de crítica que pode muito bem se manter no padrão de raiz, mesmo ao reivindicar que as bases corrompidas do sistema tanto podem amplificar suas baterias frente a bens e indivíduos vulneráveis, quanto podem eleger propriamente vulnerabilidades que não pretendem tutelar, das quais não pretendem proteger ou se ocupar.

Logicamente, o pilar teórico de que o sistema jurídico-penal, sumamente as normas penais materiais, efetivamente protegem os bens tutelados in abstracto (e que os mecanismos do sistema lidam com a problemática mundana - quiçá respondendo à situação conflito e buscando a manutenção da paz social) é carente de sustentação, e já não consegue um embasamento suficientemente crível na maioria das vezes. Não consegue, aliás, pela própria chaga denunciada constantemente pela matriz crítico-criminológica que opera em seu discurso tanto de forma endógena quanto exógena ao sistema, desenvolvendo constatações sobre as motivações primárias das normas e/ou sobre os efeitos derivados ou secundários de sua aplicação que passa longe do ideal. Enfim: o sistema jurídico-penal e as normas penais-materiais como instrumentos protetores nunca ganham inteira credibilidade diante do confronto com dados notórios de seu funcionamento real. Contudo, é importante que seja dito, há uma inegável senda de discussão em relação a uma série de ausências ou lacunas nessa proteção (mesmo em tese) que são um conjunto que merece, paradoxalmente, ser alvo de críticas de mesma matriz e mesmo quilate. 
Certas ausências (supostamente) protetivas de atuação do campo político-criminal não são fruto racional de um controle de expansão ou de uma atuação que se perfaz mínima ou vacilante por força de discursos de minimização penal ou por influência crítica (criminológica). Assim, o são, lacunas de atuação, pelo fato de que sua tutela esbarra em reconhecimentos e em valorizações políticas que - também, seletivamente - o sistema e seus meandros não parecem estar dispostos a assumir ou a defender. Mesmo discursos de cunho crítico da seletividade tutelar e pragmática do sistema jurídico-penal por vezes não atentam para a flagrante constatação de que é preciso discutir as seletividades - no plural - e que entre essas, é preciso discutir a seletividade que se manifesta quando a crítica visa barrar reconhecimentos e estatutos políticos como não passíveis de agenda legítima.

Em relação ao reconhecimento valorativo de certas pautas e direitos, via criminalização ou via trato político-criminal das mesmas, não há propriamente um contraponto, mas um obscurecimento da discussão sob a bandeira de que não podem ser objeto de ideário crítico esclarecido: seriam discursos punitivistas e crédulos no sistema travestidos ou degenerados, ou seria uma espécie de falso ideal crítico a ser corrigido ou defenestrado.

O presente trabalho se inscreve exatamente nesse ponto da discussão: através de recensão teórica sobre os conceitos e sobre as ideias-força que movem a controvérsia, visa debater e, sob certo aspecto, afirmar (I) a existência de conteúdo crítico legítimo em algumas propostas que não são puramente minimalistas ou que não visem a abolição do trato penal como ponto ótimo, e (II) a possibilidade de existência de um conteúdo crítico-reflexivo que, sem defender crenças metafísicas e bravatas em relação à política-criminal e suas possibilidades, possa assumir como importantes ou necessárias, mesmo, considerações sobre implementos do sistema e mesmo a alteração inovadora de tipos penais.

Essa lógica se dará a partir (III) especialmente do pano de fundo da discussão sobre a necessidade de criminalização exclusiva da homofobia no sistema penal pátrio, e (IV) da defesa de um ponto de vista que coloque tal hipótese como igualmente alinhada aos cânones critico- 
criminológicos, visando desbastar a alegação de contradição (ideológica) em termos.

\section{POLÍTICA CRIMINAL E CRIMINOLOGIA: DA (INICIAL) LEGITIMIDADE DE UMA DISCUSSÃO CRÍTICA DIAMETRALMENTE AUTOCRÍTICA}

Não seria possível abordar com toda a profundidade devida de maior fôlego o desenvolvimento histórico e as premissas do universo inapreensível que compõe a própria glosa do que seria uma criminologia de cunho crítico. A definição comporta uma série de elementos que tornariam uma explanação além de longa e dificultada, incompatível com a proposta aqui ofertada. Portanto, assumir-se-á uma digressão bastante modesta por alguns dos elementos principais das visões com as quais se quer propor o diálogo presente. Dessa maneira, caberia dizer, em dois tempos, que: em uma definição generalista inicial, seria possível marcar como crítica toda aquela leva de pensamento que retira o foco criminológico do homem delinquente e de suas adjacências causais, e o coloca no sistema em si, enquanto reator social. Avançando na especificação, assumir-se-á como crítica, especificamente, uma visão que mira a práxis sistemática, com elementos notáveis de materialismo histórico, para denunciar as contradições do próprio sistema (e do próprio Direito, em si) em relação ao caráter seletivo e pontual que os mesmos assumem perante a lógica capitalista.

Os influxos ou rescaldos morais (MASCARO, 2013, p. 67) que essa própria lógica jurídica calcada na forma político-capitalista imprime e busca naturalizar, fazem do sistema, como um todo, um organismo viciado no qual não se poderia efetivamente confiar de forma endógena para que o mesmo seja vanguarda ou propulsão de emancipações revolucionárias pessoais, libertárias, sexuais, etc., como ligeiros exemplos. Certos estamentos discriminatórios estão profundamente enraizados não só nos discursos e aparatos jurídicos, mas na forma política que os anima, engendrada a partir do próprio capital e sua aparelhagem (MASCARO, 2013, p. 65-66). Nesse viés, tradições e imposturas morais úteis à 
manutenção de antigos controles biopolíticos se mantêm passíveis de apropriação pelo Estado e pelo Direito, mesmo que as formatações destes sejam cambiantes estruturalmente a partir das revoluções burguesas modernas e da hegemonia do liberal-contratualismo como moldura autoproclamada democrática por excelência,

Dessa maneira, a partir de uma crítica assim tida, toda e qualquer propagação de atividade político-criminal que não seja de retração deveria ser em tese (por genuínos críticos) vista com desconfiança, do mesmo modo que retrações deveriam eventualmente ser festejadas como símbolos de um sistema perverso que, de um jeito ou outro, se apequena e assim ocupa menos frentes em sua atuação nefasta.

Ocorre que o dado ou ideia que justamente se quer ou consegue obnubilar é a de que essa própria retração não raramente - em relação a algumas agendas - é justamente o mecanismo-base do próprio sistema fugindo de qualquer assunção ou de qualquer pertinência a ser conferida. Dito de forma mais direta: trata-se do sistema, por vezes, negando ênfase a temáticas ou conceitos plenos de potencial crítico, justamente pelo fato de que o arcabouço do establishment jurídico-penal não busca, via influxos políticos, conferir destaque para certo rol de direitos e, em última análise, certas causas ou certas pessoas.

Fora gerado um padrão discursivo - mesmo dentre a crítica mais esclarecida - que prevê a barragem a certas amplitudes de consideração, e não tarda em afirmar categoricamente que só há uma via linear a ser percorrida por uma agenda verdadeira ou legitimamente crítica: aquela que condiz exclusivamente com embates políticos minimalistas enquanto plataforma tópica, visando sempre um horizonte - ainda que plataforma utópica - de abolição. Em resumo: perderia o valor e o simbolismo ideológico uma crítica não forjada na visualização da abolição penal como norte a ser almejado - consideradas assim, desde fracas, até não-verdadeiramente críticas, posturas que destoem desse quadrante. Uma visualização que nega inclusive uma "função de esclarecimento" que possibilita o trabalho criminológico com o sistema sem que haja subordinação ou absorção da criminologia perante seu funcionamento ou perante os estamentos dogmáticos (na linha do que preconiza Cf. ALBRECHT, 2010). 
Logicamente, uma matriz de pensamento que prime pela influência materialista a partir de uma crítica criminológica embasada em constatações de cariz marxista (como os mais potentes discursos criminológico-críticos o são), tem naturalidade em se demonstrar favorável à tópica/utópica que contempla o abolicionismo (tal movimento da extirpação dos resquícios da lógica do capital e de seu correlato Direito de axiomas burgueses e permanências positivistas - BATISTA, 2014, p. 86). Porém, mesmo nessa linha, é de se salientar que na evolução teórica proposta pelo próprio discurso marxista-materialista, também haveria legitimidade em um momento inicial onde o rompimento das premissas do vínculo entre Direito e capital (e sua lógica) se daria com o próprio uso enviesado de mecanismos à disposição (como para PACHUKANIS, 2017, p. 77-80; NAVES 1996, p. 115-117; e, ainda, MARX, 2012, p. 33). Não parece possível simplesmente advogar por uma parcela do discurso saltando sobre a porção inicial que é vista pelos autores-base como uma linearidade cronológica de caminhada política, até mesmo.

Obviamente há de sempre ser um uso parcimonioso para que não se recaia no já vaticinado esquadro de um discurso dito de progressista de esquerda que se desvela em um cunho punitivo crédulo. E mesmo em relação a quais os limites saudáveis desse uso, há já uma série de entraves que o desaconselham. Porém, possível é, perfeitamente, dizer que há - no mínimo - legitimidade na discussão de que se pode verificar um uso crítico ou não-alienado do sistema penal ou mesmo de implementos político-criminais. Ainda que isso se traduza em algum tipo de fusão de inovações penais típicas (o que nem precisa ser o caso, como será exemplificado abaixo). Ademais, por mais que se esteja ciente de um panorama preciso há muito desvelado por Karan (1996, p. 79), não há necessariamente que se tomar uma única rota de debate que sempre considera um reposicionamento crítico (mormente aqueles que se distanciam do abolicionismo militante) como resultado inebriado de uma renovada confiança total no sistema penal e em suas fábulas.

O fato é que não se pode simplesmente descreditar, enquanto integrantes de um panteão crítico, propostas e ideias político-criminais que sejam reflexivas e auto reflexivas. Que acoplem à crítica uma autocrítica correlata e diametral. E que estejam prontas para retrocessos 
que, de forma esclarecida, pressuponham avanços ou redução de danos colaterais.

A discussão, cingindo-se ao tema que servirá, aqui, de pano de fundo, é exemplar, no quesito: onde há ou haveria um ponto de corte crítico para estabelecer que discursos de defesa da liberdade, da dignidade e da diversidade sexual (coligados a um brado contra a prática multifacetária da homofobia), deixariam de ser legítimos e passariam a reverenciar e a engrossar a malha de um sistema moralista que maquina em sentido reacionário? Seria, em nosso sentir, impossível de estabelecer pacificamente que a viragem se daria exclusivamente no instante em que esses discursos passassem a considerar ou mesmo defender o pleito por providências político-criminais contra os agressores e suas agressões. Seria, ademais, impossível de tachar essa postura como falsa, traidora ou mesmo opaca de consciência, pelo simples fato de que uma das pautas assumidas como possíveis (ou, extremamente, defendidas) seja o conferir de valor jurídico penalmente tutelável (uma vez que é constitucionalmente relevante de forma evidente, como se demonstrará) a essas agressões.

0 argumento de que o pleito político e criminalizante é sempre equivocadamente adesista à discursividade punitivista e a endossa como um todo é ferramenta que estanca a discussão em um momento estratégico ideologicamente, mas que faz a produtividade da mesma e dos encaminhamentos eventualmente advindos se tornar amorfa ou obtusa. Não há, portanto que se desautorizar enquanto crítica uma postura que possa abrir vertente sugestiva à criminalização de condutas ou (auto criticamente) à legitimação ainda que parcial ou focada da atuação do sistema jurídico-penal.

Trata-se, inclusive, de alarmismo anticientífico e mesmo antiacadêmico a postura de procurar barrar certas pautas sob o vulto de acusações políticas de adesismo ou de alienação (ou mesmo niilismo). No caso da crítica criminológica, é impossível negar o caráter autêntico de premissas como as de Young (1993, p. 30) e Matthews (2014, p. 2829), numa linha evidentemente crítica, porém também notadamente realista, no sentido de que há compromissos políticos e defesas que se precisa, em última análise, assumir. Como bem assevera Campos (2017, 
p. 78-79), ao deixar de propor (politicamente), no quesito, assumindo postura exclusivamente reativa, a crítica (sobretudo a progressista de esquerda) perde clara oportunidade de pautar alguns vieses da discussão.

Portanto defende-se, ora, que o trato com questões como a homofobia possam livremente ser discutidos tomando-se por premissa a possibilidade aberta de falar em sua tutela penal ou criminalização, sem que isso, por si só, determine que o panteão crítico-progressista tenha sido abandonado ou invertido.

Desse modo, passa-se agora a uma ligeira exposição de elementos que conferem necessidade de trato (ou mesmo debate político-criminal) que preencha a dita dignidade constitucional do tema que já afirmamos advinda de nascença.

\section{ALGUNS DADOS SOBRE A DEFESA DA DIVERSIDADE SEXUAL E SOBRE A HOMOFOBIA NO BRASIL - A LEGITIMAÇÃO DA DISCUSSÃO POLÍTICO-CRIMINAL DO TEMA EM RESUMIDAS CREDENCIAIS}

É importante que, em um brevíssimo e resumido resgate, se discutam e exponham elementos que agiriam como credenciais da dignidade constitucional da proteção à liberdade sexual enquanto bem jurídico tutelável penalmente.

Insiste-se na premissa de que uma reflexão - mormente crítica quanto ao sistema penal não pode certamente regredir a estamentos que não englobam todo o arcabouço criminológico e as deslegitimações sistemáticas já notórias. Porém, afirma-se, igualmente, que a lacuna proposital relativa a ausência de proteção de certos bens jurídicos deve também ser alvo de uma crítica (esclarecida), uma vez que não representa menos do que o sistema exibindo sua cota patriarcal e mesmo falocêntrica (CARVALHO, 2012, p. 155) para a manutenção de establishments que redundam no panorama que a própria crítica deve eleger como oponente. E isso se percebe claramente no âmbito jurídico-penal de debate sobre a homofobia. 


\section{DO USO DO VOCÁBULO “HOMOFOBIA” NA PRESENTE CONSTRUÇÃO}

Segundo a recensão histórica promovida por Dias (2014, p. 91), o termo homofobia foi cunhado em 1972, pelo psicólogo americano George Weingerg, para identificar o medo dos heterossexuais de estarem junto de homossexuais e a auto-aversão dos próprios homossexuais - fomentada por padronizações que marcavam normalidades no limiar da pertença da orientação sexual (e de uma postura correlata) ao sexo biologicamente definido. Masiero (2014, p. 24) lembra, conjuntamente, que apesar de o termo referir-se à atitude extrema de apreensão psicológica, ele é, hodierna e comumente, utilizado tanto pelos poderes executivo e legislativo, bem como pelo colóquio dentre os movimentos $\mathrm{LGBTI}^{2}$, para designar outras formas de hostilidade, correlacionando todas as maneiras de preconceito sexual (expressão que seria inclusive mais adequada).

Não se pode negar que a construção de políticas com base numa identidade sexual (binária, heteronormativa e padronizada) limita o público alvo a ser contemplado e restringe o exercício livre da sexualidade. E não apenas no campo de vista propositivo, como naquele que nega à liberdade sexual tão brutalmente ofendida e circunscrita (como se verá em alguns elementos fáticos ora apresentados, infra), mas igualmente no campo da proteção (ou tentativa de) via estabelecimento de caráter de bem jurídico penalmente relevante. Se forem pensados elementos de uma teoria que já parta do questionamento quanto às padronizações desse cariz, um arcabouço teórico-político queer, como para Carvalho (Cf. 2012), e nas bases do que expõem Sampaio e Germano (2014, p. 192), o espectro de atuação e ingerência políticas deve ter seu vetor orientado de modo totalmente distinto da discussão, também binária e padronizada, que opõe de forma pobre um punitivismo (sempre acéfalo) contra uma crítica (sempre legítima apenas na medida em que propõe abolição ou inação).

Importante salientar que para, igualmente, os limites dessa reflexão, estar-se-á falando sobre a homofobia, sem a pretensão de emplacar uma definição totalizante, e com a consciência de que é tanto possível falar sobre a mesma gama de atos de fobia/preconceito/discriminação 
de um modo geral, como, também é necessário compreender que o multifacetado universo das orientações sexuais não poderia ser agrupado genericamente (em uma categoria matriz que opõe heteronormatividade e homossexualidade baseados exclusivamente em uma dualidade de gênero ou de sexo biológico). Ou seja: tratar-se-á aqui por força de uma leitura mais simples, do conceito e do termo relativo à homofobia como o resultado da discriminação criminosa a todo grupo que exiba orientação sexual ou caracteres de gênero dissonantes dos padrões heteronormativos. Sem que isso redunde em amalgamar toda e qualquer possibilidade de orientação sexual ou fluidez de gênero (inclusive visual), dentre a ideia de homossexualidade pura e simples. É uma apropriação ou construção útil para os propósitos aqui expostos, havendo ciência quanto a isso e quanto às limitações do conceito.

Bem como não se pode padronizar a orientação sexual normal como a heterossexual, não há como seguir-se compreendendo identidades de gênero restringidas apenas à variantes de hétero ou homossexualidade, uma vez que, os diversos fatores culturais, psíquicos e genéticos podem desdobrar-se em diversas categorias múltiplas e variadas que não caberiam de ser integral e conceitualmente exploradas aqui, como por exemplo trans (NAPIARKOVSKI, 2012, p. 219-223), e também, como explicam Oliveira, Pichler e Canabarro (2012, p. 223-230), transexual, trangênero, travesti, gênero queer, transformistas e/ou crossdressers e a androginia. Se poderia ainda referir, com Masiero (2014, p. 26) e ainda com Oliveira, Pichler e Canabarro (2012, p. 232), categorias como drag queen e drag king e T-lover. Na leitura que faz de Butler (2003, p. 27), Gomes (2017, p. 91) refere, inclusive, um "fazer gênero" como ato constante e performativo, no intuito de aliviar o próprio conceito de gênero e suas circunstâncias de categorizações sempre remetidas à roupagem (mesmo literal) que paga tributo à heteronormatividade tida por padrão, tal modulações ou desvios.

Diante de diversas nomenclaturas de identificação é difícil estabelecer conceitos rígidos de diferenciação, pois ainda não há consenso, tornando impossíveis delimitações unívocas (ÁVILA, 2012, p. 444) e, dessa maneira, justifica-se o uso do vocábulo homofobia como 
emblemático para o trato do tema, sem redução do arco de possibilidades que não necessariamente estariam até de forma gramatical nele contidos.

Por fim, importante levar em conta o grau de generalização aqui possível sem deturpação, composto a partir do fenômeno ou índole daquilo que se entende pela homofobia, que pode ser tida como um vestígio de uma cultura de manutenção de uma dominação que, ao cabo, recorre como um todo ao padrão-binário totalizante (RAUPP RIOS, 2009, p. 64):

A relação umbilical entre sexismo e homofobia é um elemento importantíssimo para perceber a homofobia como derivação do heterossexismo. De fato, a literatura dedicada à homossexualidade dialoga constantemente com a noção de gênero. 0 binarismo classificatório, entre masculino e feminino, analisado nos estudos de gênero, de novo se apresenta no âmbito da sexualidade, agora através do par heterossexualidade/homossexualidade. [...] dominação masculina sobre o feminino corresponde a superioridade da heterossexualidade sobre a homossexualidade.

Se não possuem, definitivamente, as categorias acima apresentadas, as mesmas características, é possível, com alguma segurança dizer, sofrem as mesmas consequências. Da mesma homofobia.

\section{DAS CREDENCIAIS PARA O DEBATE POLÍTICO-CRIMINAL SOBRE A TUTELA PENAL DA HOMOFOBIA}

Assim, prosseguindo com Fleury e Torres (2011, p. 53 passim 59), tem se que há um discernimento importante entre os nefastos efeitos psíquicos, externos e socialmente traumáticos dentre aqueles possíveis gerados pela homofobia: preconceito é um "prejulgamento negativo de um grupo e seus membros individuais", ele predispõe-nos contra uma pessoa baseando-nos apenas no fato de identificá-la com um grupo determinado, com julgamento prévio e negativo, estigmatizando-a por estereótipos. Já discriminação é a expressão do preconceito, ou seja, é "a exteriorização, a manifestação, a materialização do racismo, do preconceito e do estereótipo".

Levando-se em conta a série de disfunções de aceitação social bilateral (entre pessoas que disseminam preconceitos e discriminam, e 
entre as vítimas de ambas atitudes - tanto como em relação de reação análoga, em vice versa), e o grau de fatores envolvidos na esquematização (como moralidade calcada em conservadorismos de padrão biológico e consuetudinário, agregados ou não a fatores de credo ou liturgia religiosa - Cf. BORRILLO, 2010, p. 51-53), seria possível já teoricamente afirmar que a manifestação de orientação sexual não tida por ortodoxa pudesse ser estopim de conflitividade social, ainda em nosso tempo. 0 sofrimento psíquico causado pelo não enquadramento binário de gênero é costumeiramente intenso (ÁRAN, 2006, p. 60), como o são seus links externos e as fricções causadas ou estimuladas por eles no convívio. Algo que tragicamente os dados de realidade não apenas confirmam.

É possível, de fato, advogar uma série de rupturas e quebras conceituais a partir de novas acepções operadas desde uma perspectiva peculiar, usando literalmente a politização de práticas, corpos e afetos (como para LOURO, 2001, p. 542, e também CARVALHO, 2012, p. 154), para a ressignificação de conceitos-chave. Mas o panorama segue necessitando de abordagem com base na hegemonia binária ainda majoritária e em suas consequências traduzidas em violências de várias estirpes por uma questão de trato com a realidade vigente em vários níveis.

Quando se parte para a análise de dados estatísticos com amostragens empíricas coletadas nas redes de órgãos, públicos e privados, que lidam com os debates atinentes, percebe-se que as mais catastróficas especulações confirmam a expectativa. Dados fornecidos por pelo menos dois relatórios detalhados oficiais ("Relatório sobre violência homofóbica no Brasil"), em versões contíguas (BRASIL, 2012; e BRASIL, 2013), bem como pesquisas em âmbito acadêmico, tal como o 5o Relatório Nacional sobre os Direitos Humanos no Brasil: 2001-2010 (Cf. NÚCLEO DE ESTUDOS DA VIOLÊNCIA - USP, 2012), apresentam conclusões que respaldam uma série de acúmulos de dados catalogados por órgãos não-governamentais - tais como o Grupo Gay da Bahia (GGB) histórico baluarte do ativismo em questão de homossexualidade no país, que sustenta relatórios de monitoramento de violência homofóbica a partir de coleta de registros e relatos de casos (Cf. GRUPO GAY DA BAHIA, 2016).

Importante frisar que os dados coletados pelo GGB são de tamanha importância factual que o State Department, dos Estados Unidos da 
América, utiliza-os em seu relatório anual sobre direitos humanos, havendo uma preferência por esses dados àqueles fornecidos pela própria Secretaria Nacional de Direitos Humanos (SNDH), por exemplo (Cf. MOTT, 2015). Os números dos relatórios ao longo do período que vai de 2011 até 2016 (atualizações anuais) desvelam um panorama impressionante. Panorama que é agravado pela constatação disposta em um dos documentos (Cf. MOTT, 2012), de que há conflito com os dados trabalhados pela SNDH, havendo clara subnotificação de casos no quadrante oficial. Não seria possível discutir a fundo nesse trabalho a veracidade dos dados da SNDH, ou a pertinência das alegações do GGB quanto à subnotificação e a motivação política da amortização dos números. Optar-se-á pelo uso dos registros provenientes das bases do GGB pela constante atualização dos mesmos, que ultrapassou em periodicidade recente os levantamentos governamentais.

Seria do mesmo modo demasiado - além de fugidio - tentar expor e catalogar toda a carga de práticas penalmente típicas ou supostamente criminosas de que são vítimas pessoas LGBTI em virtude dessa própria condição. Aqui dar-se-á, na toada do relatório GGB, ênfase ao homicídio. Dessa forma, se prossegue.

Os dados do GGB apontam para - no último relatório (MOTT, 2016, p. 1-2) um percentual de 343 mortes documentadas no ano, 173 eram gays (50\%), 144 (42\%) trans (travestis e transexuais), 10 lésbicas (3\%), 4 bissexuais (1\%), incluindo 12 heterossexuais, como os amantes de transexuais (T-lovers), bem como 1\% de ocorrências envolvendo brasileiros(as) no exterior.

Importante salientar que essas mortes (quase uma por dia ao longo de um ano) estão estritamente ligadas à condição de orientação sexual das pessoas como linha de corte para que se compute o registro. Esse é o fator que torna mais assombroso o número, dado que condições como a da homossexualidade, por exemplo, foram caractere essencial e motivador para que ocorressem as fatalidades, razão pela qual é legítimo determinar para fins de debate que foram mortes causadas (em sentido lato) pela homofobia. Desconta-se aqui os números mencionados no relatório - mas sem dados registrais precisos - de pessoas que foram assassinadas inclusive por serem confundidos com gays e mesmo pessoas 
com grau de parentesco ou que tinham algum tipo de ligação qualquer com as vítimas (MOTT, 2016, p. 2).

Apenas em casos de homicídios de pessoas trans nessas mesmas circunstâncias, os dados mostram, por exemplo, que (de acordo com o Projeto de Monitoramento Trans Respect versus Transphobia) a taxa das ocorrências no Brasil equivale a cerca de $51 \%$ de todas ocorrências da América do Sul (Cf. TRANS RESPECT VERSUS TRANSPHOBIA, 2015). Números que anda têm agravados contra si o fator de que a atuação do sistema jurídico-penal (e aqui mormente das agências iniciais - Polícias Militar e Judiciária), obedece igualmente padrões heteronormativos ou heterossexistas que dificultam a coleta de dados e a confirmação das nuances homofóbicas dos crimes (bem como constrangem vítimas e potenciais vítimas a buscar abrigo dessas agências - Cf. MOTT, 2016, p. 4). Os números na prática podem ser ainda mais alarmantes (com a cautela de não vaticinar que, de fato, o são, ou muito provavelmente o sejam), mas apenas uma exposição tomando-os como condizentes já é o suficiente.

Parece difícil não assentir que há um descalabro alarmante na nota de orientação sexual ou gênero que faz desse tipo de elemento uma tomada de risco (de vida) constante entre esses grupos de pessoas. E que há uma afronta crucial às liberdades individuais aqui, o que por si já poderia garantir a entrada do tema (criminalização da homofobia) no rol de discussões política e constitucionalmente legítimas. Se o interesse nessas rápidas linhas residia em apresentar credenciais para que esse debate fosse possível, se crê que, ainda que de forma resumida, assim estejam, plenamente. Mas ainda há mais.

Como dispõe Masiero (2014, p. 77), as questões relativas à luta pelos direitos das pessoas LGBTI já não se cingem exclusivamente à quebra de barreiras de costumes ou a catalisadores inicias de ares de movimento social circunscrito, tais como a conscientização em relação ao perigo do contágio pelo HIV em práticas sexuais. As demandas se filiam àquelas que convergem para necessidades de reconhecimento e afastamento de opressões dignas de figurarem no âmbito da luta por cidadania, em si. Canfield (2015, p. 105) também enfatiza que as lutas das pessoas LGBTI focalizadas em movimentos caminham para uma conscientização de minoria que já discute em patamar de voz para pressão em relação a 
influxos legislativos e mesmo político-criminais. Não parece que haja simples abertura de tutela (dignidade), mas de plena necessidade constitucionalizada de tutela penal (DOLCINI, MARINUCCI, 1994, p. 150).

A questão da agressão (sob vários prismas) às pessoas do espectro LGBTI parece culturalmente epidêmica em um largo grupo de países, sendo que os números brasileiros podem mesmo representar um triste panorama médio desse tipo de ocorrência. O próprio Conselho das Nações Unidas para os Direitos Humanos, em documentação e manutenção de hotsite específico sobre a temática (Cf. UNITED NATIONS HUMAN RIGHTS, 2012) propõe que os Estados, em matéria de tutela de direitos LGBTI, destaquem a proteção dos indivíduos de violência homofóbica e transfóbica, impeçam a tortura e o tratamento cruel, desumano e degradante das pessoas LGBTI, revoguem leis que criminalizam a homossexualidade e o estilo de vida das pessoas transexuais, e proíbam a discriminação com base na orientação sexual e na identidade de gênero. Bem como salvaguardem a liberdade de expressão, de associação e de reunião pacífica para todas as pessoas LGBTI.

Ainda, na cartilha que leva o mesmo nome da campanha, "Nascidos livres e iguais" (UNITED NATIONS, 2012, p. 14-17) , a entidade expõe a violência homofóbica como um problema supranacional, e defende que a proteção das pessoas LGBTI é um dever dos Estados através de implementações políticas que atuem tanto coibindo as práticas discriminatórias quanto refreando políticas públicas que soneguem direitos (como é o caso da reversa criminalização de práticas homossexuais em vários ordenamentos jurídicos ao longo do globo).

Reconhecer que o debate se impõe em relação a um bem jurídico flagrantemente passível de tutela penal é imperativo, em que pese a discussão sobre a estratégia e a legitimidade punitiva frente aos imperativos crítico-criminológicos ainda não tenha se apresentado (virá logo abaixo no seguinte tópico). 0 fato é que não há como seguir normalizando a discussão, colocando-se em prática, inequivocamente, uma espécie ou formato mediato de homofobia, que é a constante diluição da motivação específica desse tipo de criminalidade brutal dentre fatores que visam tirar essa condição/orientação das vítimas da posição de destaque em relação ao motivo da agressão e às consequências da mesma. 
A hipótese, diretamente exposta, com a qual se trabalhará, é a de que no caso do combate à homofobia e a suas conjunturais violências, o discurso reacionário e antidemocrático costuma ser justamente aquele que barra o trato jurídico-penal da questão, momento em que os brados críticos e minimalistas militam justamente em prol do establishment que se mantém confortável com a inatividade no quesito.

\section{CRIMINOLOGIA(S) CRÍTICA(S) E CRIMINALIZAÇÃO DA HOMOFOBIA}

Não há dúvida que idealmente, para além de se pensar em perspectivas de abolição ou alternatividade de âmbito jurídico do conceito de sanção, uma vez cogitado ou assumido o uso do Direito Penal e/ou da punição criminal para fins de proteção de bens jurídicos, ele deve ser pouco aplicado ou estritamente controlado. Para Zanoide de Moraes (2006, p. 409), isso se justifica: em primeiro lugar, porque a aplicação da sanção pressupõe que já foi cometido um dano social relevante e que o Estado, em várias áreas de atuação (preventiva, educacional, extrapenal etc.), não conseguiu evitar o crime (o que questiona o próprio caráter de alerta ou ameaça - e sua eficácia - que a justificação protetiva possui). Em segundo lugar, não se deve aceitar como normal a alta incidência da sanção penal, pois isso caracteriza uma falta de legitimidade das escolhas político-axiológicas em face de uma parcela do grupo social, sendo o crime uma manifestação ilegítima daquela escolha.

Não se nega também que toda uma linha de pensamento minimalista/ crítico penal se orienta por uma inescapável constatação: sequer a tese de que a aplicação de pena seria uma infeliz necessidade política não desmonta o predicado de que - mesmo reduzida ou racionalizada - essa aplicação engrossa um vórtice de violências e contra violências da qual a lógica punitivista se alimenta, o que o Estado politicamente chancela. São opiniões de Baratta (1997, p. 64) para quem mesmo a raiz liberal do modelo punitivo moderno não impediu que, a contrassenso, a expansão da malha político-criminal e das esferas de legitimação punitiva estatal se ampliassem. Mormente diante do contexto de uma "Sociedade do Risco", 
conforme, entre outros, Souza (2007, p. 109), onde o antes "remédio amargo" (a ser usado com parcimônia) da visão liberal fora assentido enquanto última panaceia esgarçável até limites impensáveis e ofertado como solução plausível para uma nova gama de perigos e conflitos.

Wermuth (2011, p. 44) também se alia à ideia de que a expansão penal se aloca nos interstícios fomentados pelo binômio da forma como a insegurança é discutida na sociedade atual: e sumamente pela falácia consistente na ideia de que sempre falta algum resquício de campo que ainda não fora contemplado pela tutela penal, que estaria assim sempre carente de ampliação, até o ponto ótimo onde seria suficiente para estancar as práticas delitivas - eficientismo penal, na visão de Baratta (1997, p. 65).

Do ponto de vista da crítica externa, (tomando-se a noção de ALBRECHT, 2010, p. 137 e seguintes), o discurso criminológico oferece formidável arcabouço que não busca necessariamente (mas também) o trabalho com as antinomias internas da justificativa penal, e sim um embate exógeno. A criminologia crítica, assim aglutinada e aqui tida como grande universo dos discursos de deslegitimação, utiliza constatações empíricas e objeções políticas baseadas no mau funcionamento constatado e nos rotos pilares políticos da intencionalidade punitiva. Portanto, oferece armas tanto contra a proposta teorética e ideário político de necessidade eficientista de expansão, quanto oferece grau fortíssimo de denúncia quanto a atuação desastrosa do sistema em relação a alguns de seus objetivos-promessas alardeados, em termos de baixo resultado eficiente. Importante, aliás, deixar claro que a nãoeficiência atua de modo bipolar, sendo que fatores como a seletividade, a leniência, o racismo, o machismo e mesmo a heteronormtividade são escopos tanto para que se criminalize pessoas de forma ilegítima quanto para que o próprio sistema (ou sua inação), gere ou estimule vitimizações do mesmo modo.

Nesse aspecto, foi Larrauri (2000, p. 219 e seguintes) quem trouxe o cerne da discussão, ao focalizar que após o florescimento eminentemente crítico - especialmente nos anos 60 do século XX - das lutas de movimentos sociais e assim ditas minorias, sua defesa e seus discursos migram para uma nova fase de propositividade que é eivada por conflitos 
internos: se discursos como o do womens lib ou o black power conseguiam discernir que toda a estrutura social, política e jurídico-estatal estaria contaminada com (nos exemplos, respectivamente) lógicas fundadoras de raiz machista ou racista, não era facilmente crível que se poderia postular uma cobrança por maior atuação social, política e punitiva das agências e standards para combater esses próprios estamentos. Enquanto o discurso crítico era uma oposição frontal e abstrata ao sistema, de modo geral, tampouco os encaminhamentos e efetivos resultados do discurso pareciam se concretizar em fatos. Havia, pois, o impasse.

A tônica desse impasse se agrava pela cada vez maior (e benvinda, sob vários aspectos) agudização da crítica, que construiu um panorama a partir da varredura total da própria legitimação estatal. Somada a ela, indícios claros de que o sistema punitivo (sobretudo o ambiente carcerário onde redunda boa parte desse sistema), era ele próprio uma consequência direta da lógica penal que não parecia servir para nada a não ser para mais um ciclo de violação a outros direitos humanos (ou aos mesmos que os grupos defendiam, tais as vítimas de violências perpetradas por agentes policiais, por exemplo). Discursos de evidentes ataques (esquerda) e implemento (direita) frente ao sistema punitivo estatal borram suas fronteiras e geram conflito ideológico (esquerda) e novas possibilidades de uso discursivo (direita) - (WERMUTH, 2011, p. 65) a partir daí.

Se fincados os parâmetros necessariamente nesse diapasão, logicamente se estará fixado o debate em termos de baixa solubilidade. Talvez porque haja outras arestas ou necessidades em jogo, não raramente esquecidas. Carvalho (2012, p. 200) começa a abrir esse leque quando busca um repensar teórico-jurídico que seja não ajustado, mas preconcebido a partir de novos elementos, que fujam do binarismo (o que se pode a grosso modo resumir como uma teoria queer pensada para o direito). Assim, seria infrutífero seguir a pensar a questão da homofobia isolada de contextos sociais como se fosse mais um possível case de catálogo onde a discussão se resolveria eternamente entre o movimento pendular da punição-crença acéfala no discurso versus a crítica que interpõe a falência do sistema a qualquer tentativa de tutela. 
Com Carrara (2010, p. 319) tem-se que, adotar a Constituição como parâmetro positivo para a aferição de bens jurídicos penais, encontrando permissão para a tutela penal da igualdade, possibilita a identificação de duas visões. A primeira do direito como espelho da Constituição e a segunda do direito penal como instrumento de proteção apenas dos direitos fundamentais, limitando-se a tutela penal à proteção desses delitos e somente quando constatada a real necessidade da tutela criminal. 0 que, parece, é diferente de uma defesa da tutela calcada no discurso alarmista de expansão como aumento automático de uma certa eficiência.

Se o problema dogmático-penal parece passível de ser gerido nesse viés, o problema criminológico de se manter o arcabouço crítico, ao mesmo tempo em que se reconhece (também pelo viés crítico) a necessidade de tutela penal de certos direitos, segue espinhoso. E parece difícil, numa mirada rápida, de ser solucionado, eis que choque de ordem político-discursiva intenso: é ao mesmo tempo levante contra o sistema e impugnação temática de ação do mesmo sistema e seu mecanismo.

Provas e hipóteses de que a discussão não se aprisiona entre esses limites fáceis começam a surgir com a constatação de Masiero (2014, p. 124), de que no caso da homofobia e sua eventual criminalização, a ideia anti-establishment é justamente a da criminalização. Isso porque a crença média heteronormativa acusa um insuspeito abalo bifurcado, entre crer que se estaria criminalizando uma coisa naturalizada tal um direito (o preconceito e sua discriminação concernente), e perceber que se estaria ampliando o foco punitivo para áreas que atingem um público fora do igualmente naturalizado padrão corriqueiro. Tão naturalizados, nesse ínterim, estão os padrões heteronormativos, que não raramente a defesa mal disfarçada de manutenção dos padrões homofóbicos tem como um dos primeiros focos o apelar justamente para as fundações democráticas mais básicas, e não raramente se esquivar procurando um transmutar em defesa de uma livre expressão - ou algo que o valha (SANTOS, 2016, p. 50-67).

Uma ideia minimalista e não criminalizadora, pois, nem sempre é fruto de um discurso crítico e racionalizante em relação ao sistema jurídico-penal, mas pode significar puro adesismo conveniente aos 
padrões antepostos. É o que Campos (2017, p. 84) denomina sob a alcunha de "delitos invisíveis", relativamente a vitimizações que (ao contrário do que figura padrão hiper-criminalizador normal), não seriam agenda importante.

A discussão foge, inclusive, em graus basilares, da pecha que procura aprisiona-la em uma contenda sobre crenças ou oposições genéricas no sistema, e igualmente foge da ideia de que se estaria procurando reverter o cânone crítico para criar uma expansão benéfica do sistema penal. Em um primeiro momento, é visível que a legitimidade dessa proteção se destaca no panorama de liberdades fundamentais tuteláveis (e em um sistema que oferece grau distintivo a uma série de bens jurídicos até menores, não faria sentido não haver essa tutela - salvo se para fins extremistas de abolição, o que não parece o caso de algo plausível, nem próximo, muito menos imediato). Em segundo lugar, não há a necessidade obrigatória de criação textual de quaisquer tipos nem proteções de bens inventados. Basta que a lei reconheça que a motivação homofóbica da prática de certos crimes seja evidentemente assumida como possível e como plausível de ser desvalorada dogmaticamente. É a afirmação de uma diferença qualitativa, como diz Masiero (2014, p. 125) ou mesmo acréscimos qualificadores, como propõe Carvalho (2012, p. 198).

Ademais, cabe identificar as duas pautas distintas do movimento LGBTI, no plano político criminal, que são apontadas por Carvalho (2012, p. 194). A primeira é a (a) pauta negativa (limitadora da intervenção penal), nas esferas do direito e da psiquiatria, voltada à despatologização e à discriminação da homossexualidade; e a segunda é a (b) pauta positiva (expansiva da intervenção penal), no âmbito jurídico, direcionada à criminalização de condutas homofóbicas. Não cabe qualquer tipo de interdição ou trunfo em relação à ideia de que se pode defender (a) e também (b), como se houvesse proibitivo em identificar tanto a necessidade de enxugamentos sistemáticos quanto a valoração que o bem jurídico deve possuir ou adquirir. Igualmente, não cabe barrar a ideia de que é possível que o conteúdo do pensamento crítico seja auto reflexivo ao ponto de admitir fissuras ou mesmo modulações - que não devem ser retroativamente julgadas como espécie de traição ou implosão interna. Não há heresias ou posições imutáveis a cobrarem tributo. 
Exemplificativamente, não há qualquer seriedade crítica em deixar - forçosamente - de reconhecer que existe dignidade e necessidade de tutela (criminal) de atitudes como as motivadas por racismo e violência de gênero. Assim como a questão da homofobia, a identificação crítica maior se dá quando ocorre o desvelar do senso comum e do reacionarismo previsível em se transmutarem subitamente em minimalismo e até abolicionismo penais: diante de circunstâncias em que o indivíduo integrado ao establishment normalizado pode incomumente vir a ser objeto da malha punitiva, o discurso se altera vertiginosamente - e aí parece ser um campo para a crítica radical fincar diretrizes. Pois nesse aspecto Carvalho (2012, p. 200-201) preconiza que há a necessidade tão politicamente flagrante quanto na questão da violência doméstica ou do racismo (figuras já contempladas pelo arcabouço penal-legislativo), de se reconhecer que há espaço para a tutela penal.

Igualmente, fica o alerta propugnado por Masiero (2013, p. 183) de que a falácia de que se pretende em discursos dessa monta, substituir toda e qualquer atividade, política pública ou mesmo tomada de consciência por uma crença integral na esfera punitiva é vazia: jamais se pode dizer que uma mudança cultural pode advir exclusiva ou mais certeiramente de um único movimento estatal e sumamente de uma ação criminalizadora ou punitiva. É uma promessa de baixa potência, ou até delusional.

A ideia de coligar toda e qualquer ideia de tutela penal às versões ou níveis mais rasos e inconsistentes de debate - ou antes, da própria discussão sobre a legitimidade da própria ideia - é estratégia nefasta, e digna de tudo aquilo que uma crítica genuína deveria visar combater.

\section{CONSIDERAÇõES FINAIS E PREMISSAS CONCLUSIVAS}

Desagradavelmente obtusa a noção de que há um pacote imperativocrítico a ser assumido inteiramente e que as bases desse pacote são préestabelecidas por parâmetros canônicos forjados de maneira anacrônica.

Assim, é possível aferir que muitos dos ataques à ideia ora apresentada tanto como plausível como quanto defensável são oriundas de duas matrizes principais: 
I - A de uma visão crítica sempre temerosa de que seu discurso seja capturado ou falseado por uma fala opositora cuja tarefa seria amenizar e até esterilizar o potencial e os devires possíveis;

II- A de uma visão estritamente conservadora, que identifica na postura um abalo real de certos padrões do establishment.

Nesse sentido, há uma curiosa inversão de papéis que se verifica em relação ao tema - a necessidade ou possibilidade de implementos jurídico-penais ou ampliação da malha a partir de novas criminalizações:

III - A ideia de uma postura crítica e filiada a padrões de defesa de liberdades individuais e de combate ao conservadorismo imanente ao sistema jurídico-penal passa a uma categoria de receio e reacionarismo peculiares, que nega a qualquer possibilidade propositiva o distintivo de crítica verdadeira, por considerar que um padrão propositivo - e não reativo - foge ao compromisso crítico mais puro;

IV- Já a ideia de um conservadorismo embasado na mitologia da crença do boost eficientista que geralmente tem na expansão e ampliação da malha punitiva (de qualquer espécie) sua tônica passa a, estranhamente, advogar por teses de racionalização, quando não de enxugamento, minimalismo ou até inação/abolição do sistema. Tudo para evitar que ele tutele pautas que não se coadunariam com o tipo de eficientismo, o tipo de ação e o tipo de vitimização que seus padrões morais consideram valorado;

Dito isso, se expõe como três premissas conclusivas finais, as constatações que:

V- Não há contradição entre uma visão crítica (criminológica) que tomada tanto por ares de realismo, como por sensibilidade diante de graves violações de liberdade, possa ser crítica também no sentido propositivo, ao perceber que os mecanismos punitivos não apenas mostram sua perversa seletividade à moda de atuações coordenadas contra alvos pré-estabelecidos. A seletividade também opera quando se promove uma deliberada ausência de tutela de certas violações gravíssimas, que parecem ser um ponto de corte ou ruptura para a avaliação do próprio conservadorismo do sistema;

VI- Pugnar pela existência de legitimidade política de um debate e pela existência (flagrante) de dignidade constitucional para a tutela de 
um bem jurídico em âmbito penal não é uma abertura conceitual para que se assuma o discurso do eficientismo, do alarmismo e para que - de forma sofista - se diga que há ali um revertério da defesa garantista de liberdades e de parcimônia nos âmbitos de atuação do sistema. 0 que abre flanco para a última conclusão que é a de que:

VII- Já é tempo de uma visão consagrada como crítica perceber que não se pode trabalhar as visões políticas como ideologias aprisionadas e estanques, onde alguns compromissos e imperativos éticos são usados como escudo para que se mantenha uma postura não reflexiva $\mathrm{e}$ desprovida de autocrítica e de possibilidades e testes (avanços e mesmo recuos) de posicionamento.

\section{NOTAS}

1 O presente artigo traz algumas conclusões parciais das investigações conduzidas no Projeto de Pesquisa Estado de Direito, Sistemas de Justiça e crítica jurídica: horizontes de uma 'nova politica'.

2 A sigla LGBTI é uma ampliação de definições genéricas para grupos que englobam pessoas que ostentam preferências ou sentimentos de sexualidade que diferem do padrão binário de gênero embasado no sexo biológico (masculino/feminino). É ampliação porque não se agrupariam corretamente todas as manifestações de orientação sexual no conceito gay (homossexualidade, popularmente associada à homossexualidade masculina, majoritariamente), nem em generalizações pejorativas, tais como GLS ("gays, lésbicas e simpatizantes). Significa a aglutinação (sem generalização) simplificadora grupal de "Lésbicas, gays, bissexuais, trans e intersexuais", sendo esses últimos, categoria que engloba pessoas com caracteres congênitos que dificultariam ou mesclariam a percepção de gênero e sexualidade que possam possuir (Cf. ARRUBIA, 2016). Mesmo a abrangência dessa sigla é em si uma simplificação (existem mais categorias que poderiam ser ali simbolizadas), porém entendemos para fins desse trabalho que um amplo e simbólico espectro geral pode ao menos ser sugerido pelas categorias que a compõe.

\section{REFERÊNCIAS}

ALBRECHT, Peter Alexis. Criminologia: uma fundamentação para o direito penal. Trad. Juarez Cirino dos Santos. Rio de Janeiro/Curitiba: Lumen Juris/ICPC, 2010.

ÁRAN, Márcia. A transexualidade e a gramática normativa do sistema sexogênero. In Ágora, Rio de Janeiro: v. IX, n.1, p. 49-63, jan./jun. 2006.

ARRUBIA, Eduardo J. ¿Iguales o diferentes? Los derechos de las personas LGBTI en discusión. In Revista de la Facultad de Derecho - Universidad de La República, Montevideo, n. 41, dez 2016. Disponível em http://revista.fder.edu. uy/index.php/rfd/article/view/554/814. Acesso em: 19 dez. 2017. 
ÁVILA, Simone. El género desordenado. Cadernos Pagú, Campinas: Núcleo de Estudos de Gênero, n. 38, p. 441-451. jan./jun. 2012.

BARATTA, Alessandro. Defesa dos direitos humanos e política criminal. Discursos Sediciosos, Rio de Janeiro, Cortesia, n. 3, p. 57-69, jan./jun. 1997.

BORRILLO, Daniel. Homofobia: história e crítica de um preconceito. Tradução de Guilherme João de Freitas Teixeira. Belo Horizonte: Autêntica Editora, 2010.

BRASIL. Relatório sobre violência homofóbica no Brasil: ano de 2011. Brasília: Secretaria de Direitos Humanos, 2012. Disponível em: http://www. sdh.gov.br/assuntos/lgbt/pdf/relatorio-violencia-homofobica-2011-1. Acesso em: 20 dez. 2017.

BRASIL. Relatório sobre violência homofóbica no Brasil: ano de 2012. Brasília: Secretaria de Direitos Humanos, 2013. Disponível em: http://www. sdh.gov.br/assuntos/lgbt/pdf/relatorio-violencia-homofobica-ano-2012. Acesso em: 20 dez. 2017.

BUTLER, Judith. Problemas de gênero: feminismo e subversão da identidade. Tradução de Renato Aguiar. Rio de Janeiro: Civilização Brasileira, 2003.

CAMPOS, Carmen Hein de. Criminologia Feminista: teoria feminista e crítica às criminologias. Rio de Janeiro: Lumen Juris, 2017.

CANFIELD, Fernanda Ferreira. 0 direito humano a (homo)afetividade e os movimentos sociais LGBT. Curitiba: Appris, 2015.

CARRARA, Mariana Salomão. Ponderações sobre a criminalização de condutas homofóbicas. Revista Brasileira de Ciências Criminais, São Paulo: Revista dos Tribunais, v. 18, n. 84, mai/jun. 2010.

CARVALHO, Salo de. Sobre as possibilidades de uma criminologia queer. Sistema Penal \& Violência: Revista Eletrônica da Faculdade de Direito, Porto Alegre, v. 4, n. 2, p. 151-168, jul./dez. 2012.

DIAS, Maria Berenice. Homoafetividade e os direitos LGBTI. 6 ed. reformulada. São Paulo: Editora Revista dos Tribunais, 2014. 
DIVAN, Gabriel. Processo Penal e Política Criminal: uma reconfiguração da Justa Causa para a Ação Penal. Porto Alegre: Elegantia Juris, 2015.

DOLCINI, Emilio; MARINUCCI, Giorgio. Constituição e escolha dos bens jurídicos. Revista Portuguesa de Ciência Criminal, Lisboa, ano 4, fasc. 2, p. 151-198, abr./jun. 1994.

FLEURY, Alessandra Ramos Demito; TORRES, Ana Raquel Rosas. A Homossexualidade e o preconceito: o que pensam os futuros gestores de pessoas. Curitiba: Juruá, 2011.

GOMES, Camilla de Magalhães. Têmis Travesti: as relações entre gênero, raça e direito na busca de uma hermenêutica expansiva do "humano" no Direito. Tese de Doutorado apresentada ao Programa de Pós-Graduação em Direito da Universidade de Brasília, para a obtenção do título de Doutora em Direito, Estado e Constituição. Brasília: UNB, 2017.

GRUPO GAY DA BAHIA-GGB. Relatórios. Disponível em: https://grupogaydabahia. com.br. Acesso em: 28 fev. 2016.

HASSEMER, Winfried. Introdução aos Fundamentos do Direito Penal. Tradução de Pablo Rodrigo Aflen da Silva. Porto Alegre: Sérgio Antônio Fabris Editor, 2005

KARAN, Maria Lúcia. A esquerda punitiva. Discursos sediciosos: crime, direito e sociedade, ano 1, n. 1, p. 79-92, jan./jun. 1996.

LARRAURI, Elena. La crisis de la criminología crítica. In: LARRAURI, Elena. La herencia de la criminología crítica. 3 ed. Madri: Siglo Veintiuno de España Editores, 2000.

LOURO, Guacira Lopes. Teoria Queer: uma política pós-identitária para a educação. Revista Estudos Feministas, Florianópolis, v. 9, n. 2, p. 541-553, 2. sem, 2001.

BATISTA, Vera Malaguti. Introdução crítica à criminologia brasileira. Rio de Janeiro: Revan, 2014. 
MARX, Karl. Crítica ao Programa de Gotha. Tradução de Rubens Enderle. São Paulo, Boitempo, 2012.

MASCARO, Alyson Leandro. Estado e forma política. São Paulo: Boitempo, 2013.

MASIERO, Clara Moura. Criminalização da homofobia e política-criminal brasileira: análise crítica do PLC 122/2006. Sistema Penal \& Violência. Porto Alegre: EDIPUCRS, v. 5, n. 2, p. 171-186, jul./dez. 2013. Disponível em: http:// revistaseletronicas.pucrs.br/ojs/index.php/sistemapenaleviolencia/article/ view/15243/10771. Acesso em: 14 nov. 2017.

. O movimento LGBT e a homofobia: novas perspectivas de políticas sociais e criminais. Porto Alegre: Criação Humana, 2014.

MATTHEWS, Roger. Realist Criminology. London: Palgrave Macmillan, 2014.

MORAES, Mauricio Zanoide de. Política criminal, constituição e processo pena: razões da caminhada brasileira para a institucionalização do caos. Revista Faculdade de Direito da Universidade de São Paulo, v. 101, p. 403-430, jan./ dez. 2006.

MOTT, Luiz. Assassinato de homossexuais (LGBT) no Brasil: relatório 2016. Disponível em: https://homofobiamata.files.wordpress.com/2017/01/ relatc3b3rio-2016-ps.pdf. Acesso em: 20.01.2018.

MOTT, Luiz. Assassinato de homossexuais (LGBT) no Brasil: relatório 2012. Disponível em: http://pt.calameo.com/read/004650218142ea882ec8a. Acesso em: 29 fev. 2016.

NAPIARKORVSKI, Federico. Vulnerabilidad de derechos en personas trans. In: Congreso internacional de investigación y práctica profesional en psicología, iv; jornadas de investigación, xix; encuentro de investigadores en psicología del mercosur, VIII, Buenos Aires, p. 219-223, 2012. Disponível em: http://www.aacademica.org/000-072/55. Acesso em: 12 dez. 2015.

NAVES, Márcio Bilharino. Marxismo e direito: um estudo sobre pachukanis. Tese apresentada ao Programa de Doutorado em Filosofia do Instituto de Filosofia e Ciências Humanas da Universidade Estadual de Campinas. Capininas: Unicamp, 1996. 
NÚCLEO DE ESTUDOS DA VIOLÊNCIA DA UNIVERSIDADE DE SÃO PAULO-NEV/ USP. 5o Relatório nacional sobre Direitos Humanos no Brasil: 2001-2010. São Paulo: NEV/USP, 2012, p. 18 e 301-309. Disponível em: http://www.usp. $\mathrm{br} /$ imprensa/wp-content/uploads/5\%C2\%BA-Relat\%C3\%B3rio-Nacionalsobre-os-Direitos-Humanos-no-Brasil-2001-2010.pdf. Acesso em: 18 dez. 2017.

OLIVEIRA, Cínthia Roso; PICHLER, Nadir Antônio; CANABARRO, Ronaldo (Coord.). Filosofia e homoafetividade. Passo Fundo: Méritos, 2012.

PACHUKANIS, Evguiéni B. Teoria geral do direito e marxismo. Tradução de Paula Vaz de Almeida. São Paulo: Boitempo, 2017.

RIOS, Roger Raupp. Homofobia na perspectiva dos direitos humanos e no contexto dos estudos sobre preconceito e discriminação. In: JUNQUEIRA, Rogério Diniz (Org.). Diversidade sexual na educação: problematização sobre homofobia nas escolas. Brasília: Ministério da Educação, Secretaria de Educação Continuada, Alfabetização e Diversidade, UNESCO, 2009, p. 64.

SAMPAIO, Juliane Vieira; GERMANO, Idilva Maria Pires. Políticas públicas e crítica queer: algumas questões sobre identidade LGBT. Psicologia \& Sociedade, Minas Gerais, v. 26, n. 2, p. 290-300, maio/ago. 2014.

SANTOS, Carolinne Nhoato dos. Discurso do ódio: o limite à liberdade de expressão e a busca pelo movimento LGBT pelo direito a não discriminação. In: OLIVIERO, Maurizio (Coord.). Direito constitucional comparado e neoconstitucionalismo. v. 2. Perugia: Universitá Degli Studi di Perugia/Univali, 2016.

SOUZA, Luciano Anderson de. Expansão do direito penal e globalização. São Paulo: Quartier Latin, 2007.

TRANS RESPECT VERSUS TRANSPHOBIA. Disponível em: http://www. transrespect-transphobia.org/en_US/tvt-project/tmm-results/idahot-2015. htm. Acesso em: 16 mar. 2016.

UNITED NATIONS. Born Free and Equal. New York/Geneva: 2012. Disponível em: http://www.ohchr.org/Documents/Publications/BornFreeAndEqualLowRes. pdf. Acesso em: 13 jan. 2018. 
UNITED NATIONS HUMAN RIGHTS. Combatting discrimination based on sexual orientation and gender identity. Disponível em: http://www.ohchr. org/EN/Issues/Discrimination/Pages/LGBT.aspx. Acesso em: 13 jan. 2018.

YOUNG, Jock. El fracasso de la criminologia: la necesidad de un realismo radical. Trad. Ramiro Sagarduy. In. . HULSMAN, Louk; RECASENS I BRUNET, Amadeu; VAN SWAANINGEN, Rene; BERGALLI, Roberto; ZAFFARONI, Eugenio R.; CHRISTIE, Nils, YOUNG, Jock. Criminología crítica y control social: el poder punitivo del Estado. Rosário: Editorial Juris, 1993.

ZAFFARONI, Eugenio Raúl; ALAGIA, Alejandro; SLOKAR, Alejandro. Derecho Penal. Parte General. 2. ed. Buenos Aires: EDIAR, 2002.

Recebido em: 04-07-2018

Aprovado em: 22-07-2019

\section{Gabriel Antinolfi Divan}

Doutor e Mestre em Ciências Criminais pela Pontifícia Universidade Católica do Rio Grande do Sul (PUCRS). Especialista em Ciências Penais, pela PUC-RS. Professor Adjunto da Universidade de Passo Fundo - RS (UPF). Membro do Conselho do Programa de Pós-Graduação na mesma instituição. Professor do curso de Maestría en Criminología Aplicada na Universidad San Carlos (Guatemala). Coordenador do Projeto de Pesquisa Estado de Direito, Sistemas de Justiça e crítica jurídica: horizontes de uma nova política - junto ao PPG/Direito da Universidade de Passo Fundo-RS. Advogado e pesquisador.

E-mail: divan.gabriel@gmail.com

\section{Carolinne Nhoato dos Santos}

Mestre em Direito pela Universidade de Passo Fundo-UPF (2016). Bolsista Prosup/Capes. Advogada.

E-mail: carolinnenhoato@gmail.com

Universidade de Passo Fundo (UPF). Programa de Pós-Graduação em Direito. Av. Brasil Leste, 285 - São José, Passo Fundo - RS, 99052-900 
